Check for updates

Cite this: RSC Adv., 2017, 7, 46329

\title{
Facile fabrication of hierarchical porous carbon for a high-performance electrochemical capacitor
}

\author{
Guixiang Du, (D)* Qiuxiao Bian, Jingbo Zhang and Xinhui Yang
}

The template method is often used to synthesize porous materials. However, removing the template during post-processing is difficult and harsh reagents are frequently used, which is unfavorable for the carbon structure. In this paper, a facile and green synthesis route is developed for the synthesis of a 3D honeycomb-like hierarchical porous carbon based on rapid thermal decomposition of the mixture of a low-cost carbon precursor (typically starch) and $\mathrm{Na}_{2} \mathrm{CO}_{3}$ followed by $\mathrm{KOH}$ activation, in which $\mathrm{Na}_{2} \mathrm{CO}_{3}$ particles are employed as the water-soluble renewable macroporous template. Benefiting from the high specific surface area (1171 $\left.\mathrm{m}^{2} \mathrm{~g}^{-1}\right)$ and the interconnected micro-, meso-, and macropores, the porous carbon exhibits superior capacitive performance, including high specific capacitance, good rate capability and excellent cycling stability. Moreover, the porous carbon-based symmetric supercapacitor delivers a maximum energy density of $33 \mathrm{~W} \mathrm{~h} \mathrm{~kg}^{-1}$ at $100 \mathrm{~W} \mathrm{~kg}^{-1}$ and presents excellent long-term cycling stability. Considering the easy-availability of the raw materials and the facile synthesis process, this environmentally friendly and cost-effective method can be expected to be widely applied, and we estimate that the obtained porous carbon could find additional applications in other fields.

Received 30th July 2017

Accepted 26th September 2017

DOI: $10.1039 / c 7 r a 08402 a$

rsc.li/rsc-advances supercapacitor is closely associated with the pore structure of carbons, and many efforts have been made to provide insight into the relationship between the electrochemical capacitive behavior and the pore structure of carbon materials with the aim of developing advanced supercapacitors. Various porous carbon materials from the early activated carbon to hardtemplated ordered mesoporous carbon, carbon aerogel, carbon nanotubes and graphene, have been designed and studied. ${ }^{8-13}$ Considerable progress has been made, however, the practical use of supercapacitors based on these porous carbon materials is greatly hindered either by the relatively low specific capacitance, especially at high charge/discharge rate due to the limited pore size distribution, or by the difficulty in the scaledup synthesis because of the complicated preparation processes and relatively high cost. Therefore, designing high performance porous carbon electrode materials with suitable pore size distribution by the simple method is a major research objective for the practical applications.

Recently, the hierarchical porous carbon (HPC) with a combination of micropores, mesopores and/or macropores, has been shown to exhibit great potential for high performance supercapacitor applications. ${ }^{\mathbf{1 4 - 1 6}}$ The hierarchical porous structures are able to exhibit the advantages of each pore size with a synergistic effect during the electrochemical charge-discharge process, which can afford both high capacitance and good rate capability, thus making the supercapacitors possess both high energy and power density. The macropores serve as ionbuffering reservoirs, giving a decreased diffusion distance; the mesopores provide the ion-transport pathways with
Key Laboratory of Inorganic-Organic Hybrid Functional Material Chemistry, Ministry of Education, Tianjin Key Laboratory of Structure and Performance for Functional Molecules, College of Chemistry, Tianjin Normal University, Tianjin 300387, China. E-mail: dugx666@126.com; Fax: +8622 23766516; Tel: +8622 23766516 
a minimized resistance; and the micropores can strengthen the electrical double layer capacitance. ${ }^{14,16}$ Therefore, combination of macro-/meso-/micropores can result in high performance electrode materials with short ion transport distance, low resistance, and large charge storage density.

To date, HPCs are accessible via hard-/soft-templating approaches and post-activation combined methods, which provide valuable information about the effect of pore size, pore shape, channel structures and other parameters on the ion diffusion and charge storage in the nanoconfined system. ${ }^{8}$ Cheng et al. prepared a 3-dimensional hierarchical porous graphitic carbon using alkaline system consisting of $\mathrm{Ni}(\mathrm{OH})_{2} /$ NiO-phenolic resin as a hard template, ${ }^{17}$ and Liu et al. prepared the dispersed carbon hollow-spheres with micropore shells and meso/macropore cores using colloidal silica as template, and there was a specific capacitance $\left(C_{\mathrm{sp}}\right)$ of $270 \mathrm{~F} \mathrm{~g}^{-1}$ at $0.5 \mathrm{~A} \mathrm{~g}^{-1} .{ }^{18}$ $\mathrm{Lu}$ et al. described the HPC obtained by post-activation of a Pluronic F127-templated phenolic resin. ${ }^{14}$ Recent reports indicate that the HPCs can be also obtained from the biomass ${ }^{19-24}$ Hao et al. have reported the HPC aerogel derived from bagasse displaying the $C_{\mathrm{sp}}$ of $142.1 \mathrm{~F} \mathrm{~g}^{-1}$ at $0.5 \mathrm{~A} \mathrm{~g}^{-1} \cdot{ }^{23} \mathrm{Lv}$ et al. have obtained the HPC based on banana peel with the $C_{\mathrm{sp}}$ of $206 \mathrm{~F} \mathrm{~g}^{-1}$ at $1 \mathrm{~A} \mathrm{~g}^{-1} \cdot{ }^{24}$ Significant advances have already been achieved in the fabrication of HPCs, however, some challenges still remain. The fabrication process is usually complicated, time-consuming and at a relative high cost in the conventional template method, which severely limit their future industrialization, and it is difficult to reasonably control the pore size in the synthesis of HPC from biomass and the electrochemical performances need to be further improved. Therefore, development a facile, economical, environmentally benign route for the rapid production of the HPC with high performance would be advantageous for their future application.

In this paper, we reported a facile and green synthesis method to prepare the 3D honeycomb-like HPC with a combination of macropores, mesopores and micropores by a simple rapid thermal decomposition (usually several minutes) of lowcost carbon precursor (typically for starch) in the presence of $\mathrm{Na}_{2} \mathrm{CO}_{3}$ templates followed by $\mathrm{KOH}$ activation. During this synthesis process, $\mathrm{Na}_{2} \mathrm{CO}_{3}$ are employed as excellent macroporous templates because they can be easily removed by washing with water at room temperature and renewed by postcrystallization. It is demonstrated that the obtained HPC exhibit excellent electrochemical performance with a large $C_{\mathrm{sp}}$ of 249.2 $\mathrm{F} \mathrm{g}^{-1}$ at $0.5 \mathrm{~A} \mathrm{~g} \mathrm{~g}^{-1}$, excellent rate capability (the capacitance retains $90.7 \%$ at $18 \mathrm{~A} \mathrm{~g}^{-1}$ ) and good cycling performance with $94.9 \%$ retention over 5000 cycles at $5 \mathrm{~A} \mathrm{~g}^{-1}$ in $6 \mathrm{M} \mathrm{KOH}$ electrolyte due to the high specific surface area and the synergistic effect of the hierarchical pore structures, indicating that the obtained HPC are a promising electrode material for application of high performance supercapacitor.

\section{Experimental}

\section{Synthesis of the HPC}

Commercial $\mathrm{Na}_{2} \mathrm{CO}_{3}$ particles and starch were directly employed as the carbon precursor and the water-soluble templates, respectively. In the typical experiment, $2 \mathrm{~g}$ solid mixture of $\mathrm{Na}_{2} \mathrm{CO}_{3}$ and starch with a weight ratio of $1: 2$ was placed in a quartz boat, which was then placed in the upstream cool zone of a tubular quartz reactor. After the reactor was preheated to the desired temperature $\left(1000{ }^{\circ} \mathrm{C}\right)$ under $\mathrm{N}_{2}$ flow, the quartz boat was shifted to the constant temperature zone by quick moving the reactor to allow the mixture to rapidly decompose at an ultrahigh heating rate. After a short-time reaction, typically $4 \mathrm{~min}$, the obtained black solid (named $\mathrm{C} @ \mathrm{Na}_{2} \mathrm{CO}_{3}$ ) was moved out of the high-temperature zone by quickly drawing the reactor, which was washed with distilled water to removed $\mathrm{Na}_{2} \mathrm{CO}_{3}$ template and dried. Then the resulting carbon (named MPC-1) and $\mathrm{KOH}$ with a weight ratio of $1: 1$ were thoroughly mixed. Subsequently, the resultant mixture was heated to $800{ }^{\circ} \mathrm{C}$ at a rate of $8{ }^{\circ} \mathrm{C}$ min and kept for $1 \mathrm{~h}$ under $\mathrm{N}_{2}$. Finally, the obtained product was washed with dilute $\mathrm{HCl}$ and distilled water to remove the residual alkali completely, followed by drying at $100{ }^{\circ} \mathrm{C}$ for $10 \mathrm{~h}$. The final product was named as HPC-1. For comparison, the solid mixture of $\mathrm{Na}_{2} \mathrm{CO}_{3}$ and starch with a weight ratio of $1: 1$ and $1: 4$ were also used to prepare the HPCs, which were denoted as HPC-2 and HPC-3, respectively.

\section{Characterizations of the HPC}

The morphologies and structures of the prepared HPC materials were characterized by field emission scanning electron microscopy (FESEM, FEI Nova Nano SEM 230) and transmission electron microscopy (TEM, FEI Tecnai G2 F20). The porous characteristic of the HPC was examined by $\mathrm{N}_{2}$ adsorption/ desorption experiments at $77 \mathrm{~K}$ using ASAP 2020 Physisorption Analyzer (Micromeritics, USA). The specific surface area was measured according to the Brunauer-Emmett-Teller (BET) method.

\section{Electrochemical measurements}

In order to evaluate the electrochemical performances of the asprepared HPCs, both a three-electrode system and a symmetrical two-electrode system were used. The working electrode was fabricated by mixing the active materials $(85 \mathrm{wt} \%)$ with $10 \mathrm{wt} \%$ of acetylene black as the conductive assistant and $5 \mathrm{wt} \%$ of polytetrafluoroethylene as a binder. A small amount of ethanol was added to the mixture to produce a homogeneous paste. Then the resulting mixture was coated onto the nickel foam substrate $\left(1 \mathrm{~cm}^{2}\right.$ ) (the mass loading in each electrode is about $3.0 \mathrm{mg}$ $( \pm 0.1 \mathrm{mg})$ ), and followed by drying at $80^{\circ} \mathrm{C}$ for $12 \mathrm{~h}$ in a vacuum oven. In a three-electrode system, platinum foil and a saturated calomel electrode were used as the counter and reference electrodes, respectively. A two-electrode capacitor was assembled by two electrodes with the same size and the same active materials loading separated by a polypropylene membrane. An aqueous solution of $6 \mathrm{M} \mathrm{KOH}$ was used as the electrolyte.

Cyclic voltammetry (CV) and electrochemical impedance spectroscopy (EIS) measurements were conducted on CHI660B electrochemical work station from shanghai $\mathrm{CH}$ Instrument Inc., and galvanostatic charge/discharge (GCD) tests were conducted on a Land cell tester. The CV measurement and GCD 
tests were performed in a potential range between -1 to $0 \mathrm{~V}$ in a three-electrode system and $0-1 \mathrm{~V}$ in a two-electrode system, respectively. EIS measurements were performed at an open circuit voltage $(0 \mathrm{~V})$ with $5 \mathrm{mV}$ amplitude in a frequency range from $0.01 \mathrm{~Hz}$ to $100 \mathrm{kHz}$.

The $C_{\mathrm{sp}}$ in the three-electrode system was calculated from galvanostatic discharge curves according to the equation of $C_{\mathrm{sp}}$ $=I t / m V$, while, for the two-electrode cells, it was calculated by the equation of $C_{\mathrm{sp}}=2 I t / \mathrm{mV}$, where $I$ is the charge/discharge current, $t$ is the discharge time, $V$ is the voltage window and $m$ is the mass of electrode materials (for the two-electrode cells, $m$ is the mass of electrode materials on single electrode).

The energy density $(E)\left(\mathrm{W} \mathrm{h} \mathrm{kg}^{-1}\right)$ and power density $(P)$ $\left(\mathrm{W} \mathrm{kg}^{-1}\right)$ of the cell in the two-electrode configuration were calculated by using the equations of $E=0.5 C_{\mathrm{sp}}(\Delta V)^{2} / 3.6$ and $P=E \times 3600 / \Delta t$, respectively, where $C_{\mathrm{sp}}\left(\mathrm{F} \mathrm{g}^{-1}\right)$ represents the specific capacitance of the supercapacitor calculated from the GCD curves in two-electrode configuration, and $\Delta t(\mathrm{~s})$ and $\Delta V(\mathrm{~V})$ refers to the discharge time and voltage change within the discharge time. ${ }^{25}$

\section{Results and discussion}

The morphologies and structures of the prepared products were analyzed by FESEM and TEM (Fig. 1). SEM images of C@Na $\mathrm{CO}_{3}$
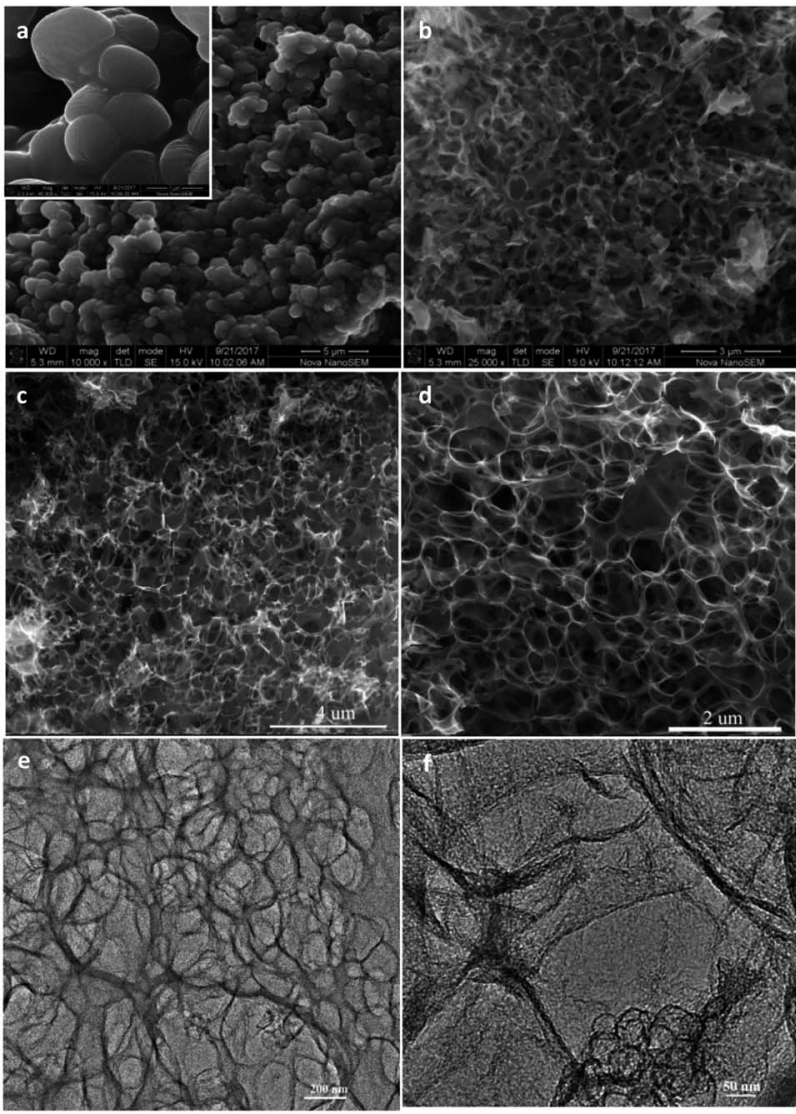

Fig. 1 SEM images of C $\mathrm{NNa}_{2} \mathrm{CO}_{3}$ (a) and MPC-1 (b), (c, d) SEM images and $(e, f)$ TEM images of HPC-1.
(Fig. 1a) show that the thin carbon layers can be formed, and the $\mathrm{Na}_{2} \mathrm{CO}_{3}$ particles (from several hundred nanometers to about one micrometer) are covered by the thin carbon layers. After easy removal of $\mathrm{Na}_{2} \mathrm{CO}_{3}$ by washing with water at room temperature, MPC-1 with obvious numerous interconnected relative uniform macroporous network were obtained (Fig. 1b), and the size of the pores is consistent with that of $\mathrm{Na}_{2} \mathrm{CO}_{3}$ particles that in $\mathrm{C} @ \mathrm{Na}_{2} \mathrm{CO}_{3}$, which signifies that $\mathrm{Na}_{2} \mathrm{CO}_{3}$ particles play an important role in the formation of main macropores. After activation of MPC- 1 by $\mathrm{KOH}$, it can be seen that the obtained porous carbon (HPC-1) still presents a similar three-dimensional honeycomb-like macroporous network structure and possesses a thin carbon walls (Fig. 1c and d). From the TEM images of Fig. 1e and f, some mesopores and even micropores can be observed, which are maybe formed by the rapid release of the gases produced by the pyrolysis of starch and by $\mathrm{KOH}$ activation of MPC-1, ${ }^{26-28}$ and the ordered lattice fringes exist on the porous carbon walls, which is due to the graphitization of the porous carbon. The interconnecting wellordered macropores and mesopores will be helpful for the electrolyte ions diffusion.

For comparison, the weight ratio between $\mathrm{Na}_{2} \mathrm{CO}_{3}$ and starch is tailored, and HPC-2 (Fig. 2a and b) and HPC-3 (Fig. 2c and d) are also obtained. When the amount of $\mathrm{Na}_{2} \mathrm{CO}_{3}$ is increased, it can be observed that some interconnecting well-ordered macroporous network structures are destroyed (Fig. 2a and b). On the contrary, the unhomogeneous macroporous network structure is gained and the carbon walls become thicker with the reducing of the amount of $\mathrm{Na}_{2} \mathrm{CO}_{3}$ (Fig. 2c and d), and a thick bulk structure is obtained under the same conditions without $\mathrm{Na}_{2} \mathrm{CO}_{3}$ particles (the inset of Fig. 2d). It also means that $\mathrm{Na}_{2} \mathrm{CO}_{3}$ particles play an important template role in the formation of the interconnected macroporous network structure and the proper amount probably could produce the promised structure with high performance. From the general
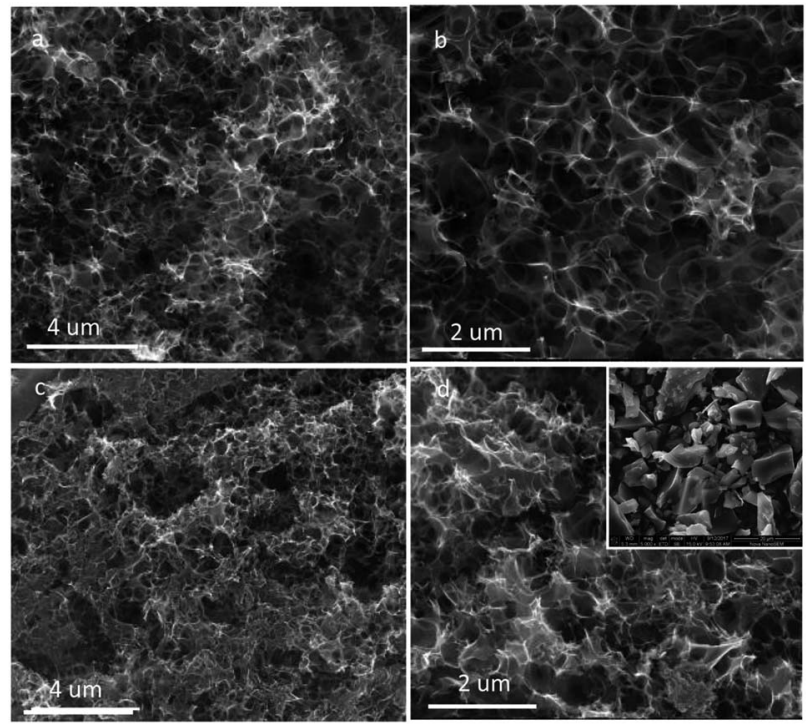

Fig. 2 SEM images of HPC-2 (a, b), HPC-3 (c, d) and obtained carbon by direct pyrolysis of starch without $\mathrm{Na}_{2} \mathrm{CO}_{3}$ (the inset of $\mathrm{d}$ ). 
morphologies, we preliminarily predict that HPC-1 maybe have better electrochemical performances.

To further characterize the pores of the HPC- $1, \mathrm{~N}_{2}$ adsorption-desorption isothermal analysis was performed, as shown in Fig. 3. The steep increase at low relative pressure $\left(P / P_{0}\right)$ indicates the formation of micropores in large quantities, ${ }^{29}$ and there exists a hysteresis loop after $P / P_{0}=0.4$, illustrating the presence of mesopores (Fig. 3a). There is no adsorption plateau near $P / P_{0}=1.0$, suggesting the existence of macropores ${ }^{23}$ (Fig. 3a), which is agreement with the SEM and TEM images. The BET surface area and micropore volume of HPC-1 $\left(1171 \mathrm{~m}^{2}\right.$ $\mathrm{g}^{-1}$ and $\left.0.3533 \mathrm{~cm}^{3} \mathrm{~g}^{-1}\right)$ are much higher than those of MPC-1 $\left(89.51 \mathrm{~m}^{2} \mathrm{~g}^{-1}\right.$ and $\left.0.0422 \mathrm{~cm}^{3} \mathrm{~g}^{-1}\right)$, suggesting that much more micropores and mesopores are produced in HPC-1 by $\mathrm{KOH}$ activation (Fig. $3 \mathrm{a}$ and the inset). ${ }^{\mathbf{2 6 - 2 8}}$ It can also be clearly seen that HPC-1 contains abundant micropores, mesopores and macropores from Fig. $3 \mathrm{~b}$. The results indicates that the hierarchical construction assembled from interconnected micro-, meso-, and macropores with high specific surface area can be easily obtained by a simple rapid pyrolysis of starch in the presence of $\mathrm{Na}_{2} \mathrm{CO}_{3}$ template followed by $\mathrm{KOH}$ activation, which will facilitate charge storage and fast ion transport, and thus could improve the electrochemical performance. ${ }^{30}$

To evaluate the electrochemical performance of the HPCs, CV, EIS and GCD measurement were carried out in a $6 \mathrm{M} \mathrm{KOH}$ aqueous electrolyte in a three-electrode configuration. Fig. 4a represents the CV plots of HPC-1, HPC- 2 and HPC-3 at a scan rate of $50 \mathrm{mV} \mathrm{s}^{-1}$. The CV profiles of all samples exhibit a quasirectangular shape, demonstrating good capacitive behavior. The current density response for the HPC-1 is much larger than that of HPC-2 and HPC-3 at the same scan rate, indicating that HPC-1 has a higher $C_{\mathrm{sp}}$, which is associated with the suppose from the SEM results. Fig. 4b displays the CV plots of HPC-1 at
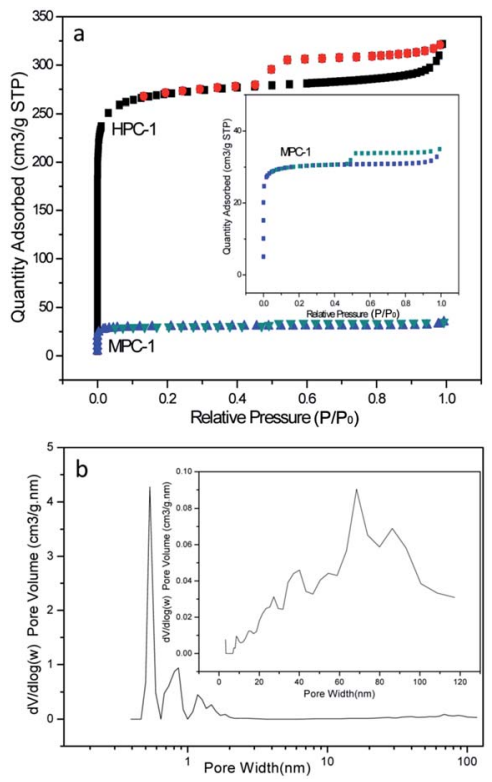

Fig. $3 \quad N_{2}$ absorption/desorption isotherm of MPC-1 and HPC-1 (a) and pore size distribution of HPC-1 (b).
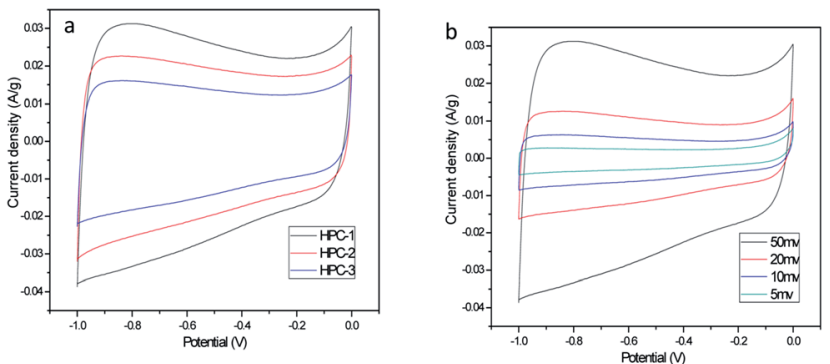

Fig. 4 (a) CV curves of HPC-1, HPC-2 and HPC-3 at a scan rate of $50 \mathrm{mV} \mathrm{s}^{-1}$ (b) CV curves of HPC-1 at various scan rates.

scan rates between $5 \mathrm{mV} \mathrm{s}^{-1}$ and $50 \mathrm{mV} \mathrm{s}^{-1}$. The obvious increase of the current with the scan rate reveals the desirable rate capability of HPC-1 electrode. In addition, the quasirectangular shape can be still maintained with the increase of potential scan rate, showing that HPC-1 possess excellent capacitive behavior at high scan rates, which may be attributed to the optimum hierarchical pore structure that combines macropores, mesopores and micropores as well as excellent electrical conductivity. ${ }^{31}$

The performance of the electrode materials are further analyzed by GCD method. Fig. 5a displays the charge-discharge curves of the obtained three HPCs at a current density of $0.5 \mathrm{~A} \mathrm{~g}^{-1}$, and Fig. 5b shows the charge-discharge curves of HPC-1 at different current density. The perfect isosceles triangular GCD curves of all the samples indicate a reversible, ideal electric double layer capacitor (EDLC) behavior, and high
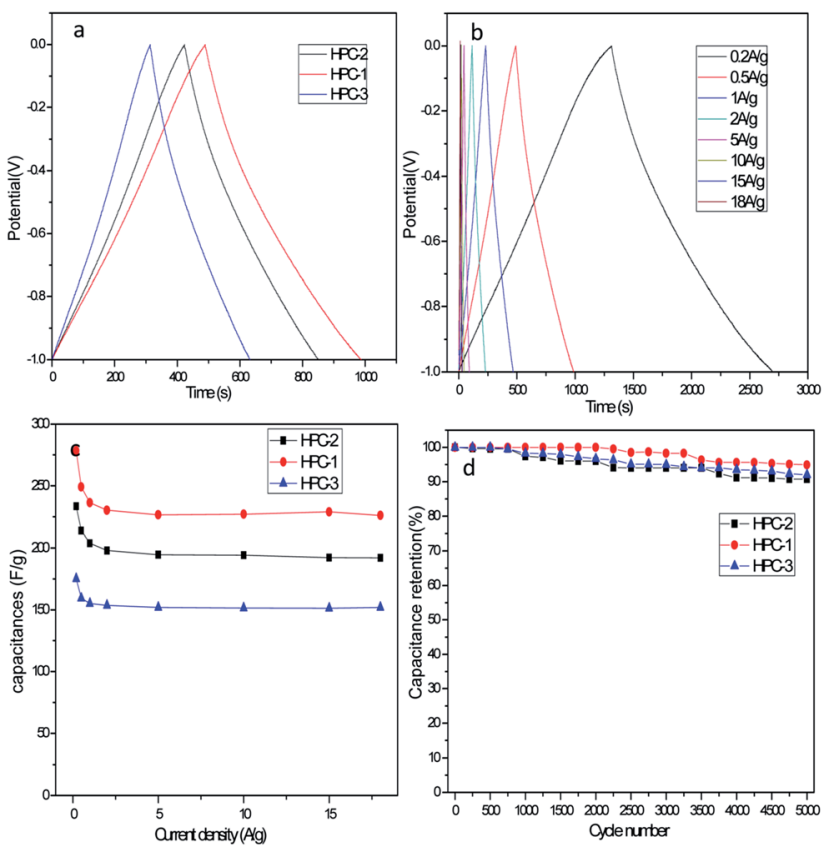

Fig. 5 (a) Charge-discharge curves of HPC-1, HPC-2 and HPC-3 electrode at the current density of $0.5 \mathrm{~A} \mathrm{~g}^{-1}$, (b) charge-discharge curves of HPC-1 at various current densities. (c) The $C_{\mathrm{sp}}$ values of the HPCs as a function of current density, (d) the cycling performance of the HPCs at a constant current density of $5 \mathrm{~A} \mathrm{~g}^{-1}$. 
charge-discharge efficiency. The discharging time of HPC-1 is obviously longer than that of the other HPCs, revealing that HPC-1 offers much larger charge storage ability, which is also consistent with the $\mathrm{CV}$ test results. The $C_{\mathrm{sp}}$ values are calculated using GCD analysis data, and the values of HPC-1, HPC-2 and HPC-3 are $249.2 \mathrm{~F} \mathrm{~g}^{-1}, 213.8 \mathrm{~F} \mathrm{~g}^{-1}$ and $159.3 \mathrm{~F} \mathrm{~g}^{-1}$ at $0.5 \mathrm{~A} \mathrm{~g}^{-1}$, respectively. HPC-1 presents the highest $C_{\mathrm{sp}}$, possibly due to its uniform and well-ordered macroporous network structure at the optimized weight ratio between starch and $\mathrm{Na}_{2} \mathrm{CO}_{3}$, which is also in agreement with the SEM images and CV results. The synergistic effect of macropores, mesopores and micropores can minimize the interfacial resistance of the charge transfer process and provide better access for the electrolyte into the entire structure. The $C_{\mathrm{sp}}$ values of HPCs exhibit an overall gradual decrease with the increase of current density (Fig. 5c), which results from the partial active material having insufficient time available for ion diffusion and adsorption at high current density. ${ }^{32}$ The calculated $C_{\mathrm{sp}}$ values of HPC-1 were 278.4, $249.2,236.3,230.3,226.6,227,228.9 \mathrm{~F} \mathrm{~g}^{-1}$ at a discharge current density of $0.2,0.5,1,2,5,10$ and $15 \mathrm{~A} \mathrm{~g}^{-1}$, respectively. Moreover, even at a high current rate of $18 \mathrm{~A} \mathrm{~g}^{-1}$, the HPC-1 can still deliver a high capacitance of $226.1 \mathrm{~F} \mathrm{~g}^{-1}$, which is much higher than that of HPC-2 $\left(192 \mathrm{~F} \mathrm{~g}^{-1}\right)$, HPC-3 $\left(151.9 \mathrm{~F} \mathrm{~g}^{-1}\right)$ and many previously reported carbon materials, ${ }^{13,23,24,33-36}$ such as hierarchical porous carbon foams $\left(182 \mathrm{~F} \mathrm{~g}^{-1} \text { at } 10 \mathrm{~A} \mathrm{~g}^{-1}\right)^{23}$ and 3D hierarchial graphene-CNT composites $\left(167 \mathrm{~F} \mathrm{~g}^{-1}\right.$ at $\left.10 \mathrm{~A} \mathrm{~g}^{-1}\right) \cdot^{33}$ The capacitance retention is $90.7 \%, 89.8 \%$ and $95.4 \%$ of the initial capacitance at $0.5 \mathrm{~A} \mathrm{~g}^{-1}$ for HPC-1, HPC-2 and HPC-3, respectively, indicating the excellent rate capability and high capacitance retention of HPC-1 during fast charging/ discharging, which are critical for high-performance supercapacitors. It may be owing to the good conductivity and well developed hierarchical porosity, in which the interconnected macropores serve as electrolyte reservoirs to reduce the diffusion distances of charges; while the small mesopores allow the fast ions transfer at high current density. ${ }^{37}$ Cyclic stability of the electrode is one of the most important factors in determining the supercapacitors for practical applications. Fig. $5 \mathrm{~d}$ shows the retention of $C_{\mathrm{sp}}$ over 5000 cycles of the prepared HPCs at a current density of $5 \mathrm{~A} \mathrm{~g}^{-1}$. It can be seen that the as-prepared electrode materials exhibit excellent cycle stability: capacity retention can be still maintained at $94.9 \%, 90.8 \%$ and $92 \%$ for HPC-1, HPC-2 and HPC-3, respectively. The excellent cycle stability should be attributed to the unique structural feature of the as-prepared HPCs.

EIS analysis is a tool to examine the electrical conductivity and ion transfer of the electrode materials. Fig. 6 shows Nyquist plots of the obtained HPCs with a frequency range from 0.01 to $100 \mathrm{kHz}$ in $6 \mathrm{M} \mathrm{KOH}$ solution. All the impedance spectra of the samples are almost similar, which contain a high-frequency semicircle and a low-frequency sloping straight line. At high frequency, the equivalent series resistance $\left(R_{\mathrm{S}}\right)$ of the electrode can be obtained from the intercept at real axis and the charge transfer resistance $\left(R_{\mathrm{ct}}\right)$ can be obtained from the radius of the semicircle impedance loop. It is accepted that the semicircle reflects the electrochemical reaction impedance of the electrode and a bigger semicircle means a large charge-transfer

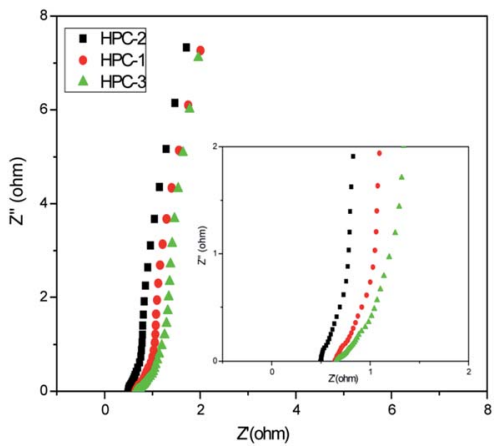

Fig. 6 Nyquist plots of HPCs electrode (the inset is the magnified plots).

resistance. ${ }^{37}$ It can be calculated that the HPCs have the low $R_{\mathrm{S}}$ values ( $0.71,0.60$ and $0.75 \Omega$ for HPC-1,2,3, respectively), and HPC- 1 has the smaller $R_{\text {ct }}$ value $(0.09 \Omega)$ than that for HPC-2 $(0.27 \Omega)$ and HPC-3 $(0.45 \Omega)$, which suggest that the HPC-1 has a low charge transfer resistance at high frequency ranges. The straight line indicates the diffusion of the electroactive species and a higher slope signifies lower diffusion rate. It is obvious that all the low-frequency lines are closer to the vertical, which also indicate their low diffusion resistance and good electrochemical capacitive properties. ${ }^{38}$ The EIS results further demonstrate that the HPC-1 has the good electrical conductivity and the ability of rapid electron and ion transport, which is consistent with the CV and GCD results.

From the practical perspective, we further investigated the electrochemical performance of HPC-1 in a symmetrical twoelectrode system in $6 \mathrm{M} \mathrm{KOH}$ aqueous electrolyte. EIS measurement reveals that the $R_{\mathrm{s}}$ values and the $R_{\mathrm{ct}}$ values are
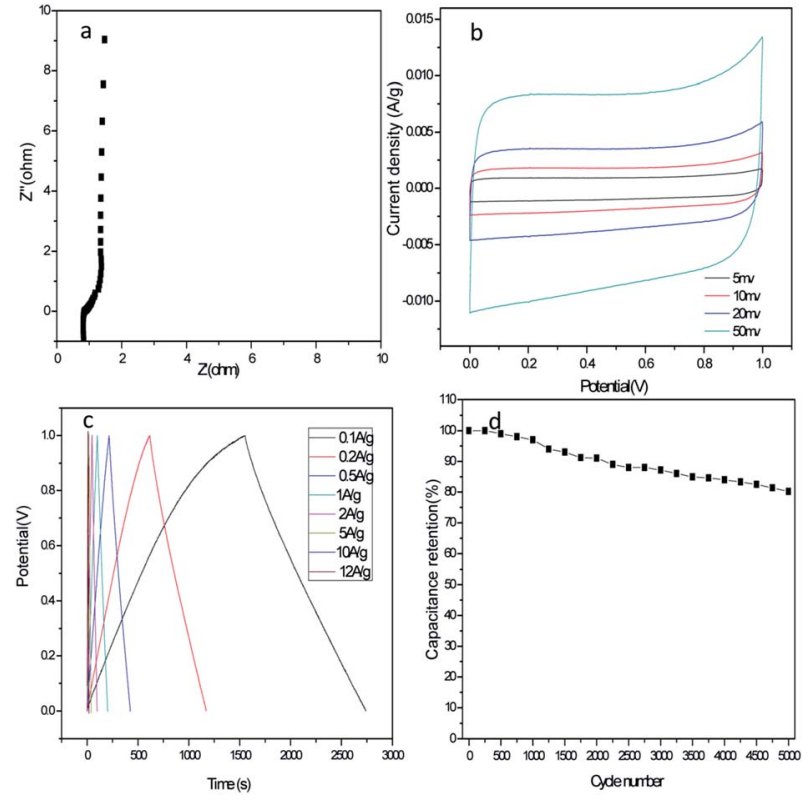

Fig. 7 (a) Nyquist plots (b) CV curves (c) charge-discharge curves at various current densities (d) the cycling performance of HPC-1 at a constant current density of $5 \mathrm{~A} \mathrm{~g}^{-1}$ in a two-electrode system. 
0.90 and $0.77 \Omega$, respectively, and slope line is closer to the vertical (Fig. 7a), indicate the low charge transfer resistance and low diffusion resistance. As expected, the quasi-rectangular CV curves at various scan rates ranging from 5 to $50 \mathrm{mV} \mathrm{s}^{-1}$ (Fig. 7b) and the isosceles triangular GCD curves at various current densities (Fig. 7c) reflect the perfect double-layer capacitive characteristics of the symmetric supercapacitor. The $C_{\mathrm{sp}}$ values of HPC-1 in the two-electrode system $\left(237.5 \mathrm{~F} \mathrm{~g}^{-1}\right.$ at $0.1 \mathrm{~A} \mathrm{~g}^{-1}, 208.8 \mathrm{~F} \mathrm{~g}^{-1}$ at $10 \mathrm{~A} \mathrm{~g}^{-1}$ ) are still impressive and comparable to many other reported high-performance carbon materials. ${ }^{13,21}$ Furthermore, HPC-1 delivers an energy density of $33 \mathrm{~W} \mathrm{~h} \mathrm{~kg}^{-1}$ at a power density of $100 \mathrm{~W} \mathrm{~kg}^{-1}$ and still remains a relatively high energy density of $29 \mathrm{~W} \mathrm{~h} \mathrm{~kg}^{-1}$ when the power density increases to $10 \mathrm{~kW} \mathrm{~kg}^{-1}$, which is much higher than that of the reportes. ${ }^{23,39,40}$ As illustrated in Fig. 7d, 80.2\% retention of the initial $C_{\mathrm{sp}}$ after 5000 cycles at $5 \mathrm{~A} \mathrm{~g}^{-1}$ suggests that HPC-1 is a promising candidate for long-term energy storage devices.

\section{Conclusions}

In summary, a facile and green synthesis route has been developed for the successful fabrication of hierarchical porous carbon materials with the interconnected macropores, mesopores and micropores from starch. HPC-1 demonstrates high $C_{\mathrm{sp}}$ of $226.1 \mathrm{~F} \mathrm{~g}^{-1}$ at $18 \mathrm{~A} \mathrm{~g}^{-1}$, good rate performance (capacitance retention is $90.7 \%$ of the initial capacitance at $0.5 \mathrm{~A} \mathrm{~g}^{-1}$ ) and long cyclic stability (94.9\% retention after continuous 5000 cycles at a current density of $5 \mathrm{~A} \mathrm{~g}^{-1}$ ) in a three-electrode system, and delivers a high energy density of $33 \mathrm{~W} \mathrm{~h} \mathrm{~kg}^{-1}$ at a power density of $100 \mathrm{~W} \mathrm{~kg} \mathrm{~kg}^{-1}$ in the symmetric supercapacitor. Such excellent electrochemical performance could be contributed to the combination of various pores: well-order macropores act as the ion reservoir and shorten the ion diffusion distance; mesopores allow electrolyte ions to transfer rapidly; micropores could significantly increase the specific surface area of carbon materials and thus enhance the electrical double layer capacitance. The excellent electrochemical properties suggest that the assynthesized hierarchical porous carbons could be a good candidate for supercapacitor electrode materials, and we believe that they would have great potential for other functional applications, such as catalyst support, gas storage and other batteries. It is to be noted that we emphasized the employing of water-soluble and renewable $\mathrm{Na}_{2} \mathrm{CO}_{3}$ as templates and provided a simple and effective synthesis method for the synthesis of hierarchical porous carbon in this paper, and the low-cost starch also can be replaced by other carbon precursors. The facile synthesis method would open up an effective route for the synthesis of many other hierarchical porous carbon-based materials in a large scale.

\section{Conflicts of interest}

There are no conflicts to declare.

\section{Acknowledgements}

This work was supported by National Natural Science Foundation of China (No. 51102180), and supported by the Program for innovative Research Team in University of Tianjin (No. TD125038).

\section{Notes and references}

1 Z. Yang, J. Zhang, M. C. Kintner-Meyer, X. Lu, D. Choi, J. P. Lemmon and J. Liu, Chem. Rev., 2011, 111, 3577-3613.

2 P. Simon and Y. Gogotsi, Nat. Mater., 2008, 7, 845-854.

3 P. Yang, Y. Ding, Z. Lin, Z. Chen, Y. Li, P. Qiang, M. Ebrahimi, W. Mai, C. P. Wong and Z. L. Wang, Nano Lett., 2014, 14, 731-736.

4 M. F. EI-Kady and R. B. Kaner, Nat. Commun., 2013, 4, 14751483.

5 W. Fan, C. Zhang, W. W. Tjiu, K. P. Pramoda, C. He and T. Liu, ACS Appl. Mater. Interfaces, 2013, 5, 3382-3391.

6 G. Sun, X. Zhang, R. Lin, J. Yang, H. Zhang and P. Chen, Angew. Chem., Int. Ed., 2015, 127, 4734-4739.

7 S. Faraji and F. N. Ani, Renewable Sustainable Energy Rev., 2015, 42, 823-834.

8 L. L. Zhang and X. S. Zhao, Chem. Soc. Rev., 2009, 38, 25202531.

9 D. S. Yu and L. M. Dai, J. Phys. Chem. Lett., 2010, 1, 467-470. 10 Y. X. Xu, G. Q. Shi and X. F. Duan, Acc. Chem. Res., 2015, 48, 1666-1675.

11 Z. J. Fan, Q. K. Zhao, T. Y. Li, J. Yan, Y. M. Ren, J. Feng and T. Wei, Carbon, 2012, 50, 1699-1703.

12 B. J. Jiang, C. G. Tian, L. Wang, L. Sun, C. Chen, X. Z. Nong, Y. G. Qiao and H. G. Fu, Appl. Surf. Sci., 2012, 258, 34383443.

13 Z. J. Li, W. Lv, C. Zhang, B. H. Li, F. Y. Kang and Q. H. Yang, Carbon, 2015, 92, 11-14.

14 W. Xing, C. C. Huang, S. P. Zhuo, X. Yuan, G. Q. Wang, D. Hulicova-Hurcakova, Z. F. Yan and G. Q. Lu, Carbon, 2009, 47, 1715-1722.

15 K. A. Cychosz, R. Guillet-Nicolas, J. Garcia-Martinez and M. Thommes, Chem. Soc. Rev., 2017, 46, 389-414.

16 F. Xu, R. J. Cai, Q. C. Zeng, C. Zou, D. C. Wu, F. Li, X. Lu, Y. R. Liang and R. W. Fu, J. Mater. Chem., 2011, 21, 19701976.

17 D. W. Wang, F. Li, M. Liu, G. Q. Lu and H. M. Cheng, Angew. Chem., Int. Ed., 2008, 47, 373-376.

18 Y. Han, X. T. Dong, C. Zhang and S. X. Liu, J. Power Sources, 2012, 211, 92-96.

19 S. Dutta, A. Bhaumik and K. C.-W. Wu, Energy Environ. Sci., 2014, 7, 3574-3592.

20 J. Deng, M. M. Li and Y. Wang, Green Chem., 2016, 18, 48244854.

21 A. Bello, N. Manyala, F. Barzegar, A. A. khaleed, D. Y. Momodu and J. K. Dangbegnon, RSC Adv., 2016, 6, 1800-1809.

22 Y. T. Luan, L. Wang, S. Guo, B. J. Jiang, D. D. Zhao, H. J. Yan, C. G. Tian and H. G. Fu, RSC Adv., 2015, 5, 42430-42437.

23 P. Hao, Z. H. Zhao, J. Tian, H. D. Li, Y. H. Sang, G. W. Yu, H. Q. Cai, H. Liu, C. P. Wong and A. Umar, Nanoscale, 2014, 6, 12120-12129.

24 Y. K. Lv, L. H. Gan, M. X. Liu, W. Xiong, Z. J. Xu, D. Z. Zhu and D. S. Wright, J. Power Sources, 2012, 209, 152-157. 
25 Y. J. Cai, Y. Luo, X. Zhao, Y. Xiao, Y. R. Liang, H. Hu, Y. L. Liu and M. T. Zheng, J. Power Sources, 2017, 353, 260-269.

26 Y. W. Zhu, S. Murali, M. D. Stoller, K. J. Ganesh, W. W. Cai, P. J. Ferreira, A. Pirkle, R. M. Wallace, K. A. Cychosz, M. Thommes, D. Su, E. A. Stach and R. S. Ruoff, Science, 2011, 332, 1537-1541.

27 J. Liu, X. Y. Wang, J. Gao, Y. W. Zhang, Q. Lu and M. Liu, Electrochim. Acta, 2016, 211, 183-192.

28 Z. Li, K. K. Guo and X. L. Chen, RSC Adv., 2017, 7, 3052130532.

29 W. Lin, B. Xu and L. Liu, New J. Chem., 2014, 38, 5509-5514.

30 Q. H. Liang, L. Ye, Z. H. Huang, Q. Xu, Y. Bai, F. Y. Kang and Q. H. Yang, Nanoscale, 2014, 6, 13831-13837.

31 W. Xing, C. C. Huang, S. P. Zhuo, X. Yuan, G. Q. Wang, D. Hulicova-Jurcakova, Z. F. Yan and G. Q. Lu, Carbon, 2009, 47, 1715-1722.

32 D. Ghosh, S. Giri and C. K. Das, ACS Sustainable Chem. Eng., 2013, 1, 1135-1142.
33 Y. Wang, Y. Wu, Y. Huang, F. Zhang, X. Yang, Y. Ma and Y. Chen, J. Phys. Chem. C, 2011, 115, 23192-23197.

34 M. Klose, R. Reinhold, K. Pinkert, M. Uhlemann, F. Wolke, J. Balach, T. Jaumann, U. Stoeck, J. Echert and L. Giebeler, Carbon, 2016, 106, 306-313.

35 G. F. Ma, F. T. Ran, H. Peng, K. J. Sun, Z. G. Zhang, Q. Yang and Z. Q. Lei, RSC Adv., 2015, 5, 83129-83138.

36 Y. W. Qiang, J. G. Jiang, Y. C. Xiong, H. Chen, J. Y. Chen, S. Y. Guan and J. D. Chen, RSC Adv., 2016, 6, 9772-9778.

37 Y. Li, Q. Wang, P. P. Liu, X. H. Yang, G. X. Du and Y. Liu, Ceram. Int., 2015, 41, 4248-4253.

38 H. J. Yan, J. W. Bai, J. Wang, X. Y. Zhang, B. Wang, Q. Liu and L. H. Liu, CrystEngComm, 2013, 15, 10007-10015.

39 L. Y. Pang, B. Zou, X. Han, L. Y. Cao, W. Wang and Y. P. Guo, Mater. Lett., 2016, 184, 88-91.

40 H. B. Feng, H. Hu, H. W. Dong, Y. Xiao, Y. J. Cai, B. F. Lei, Y. L. Liu and M. T. Zheng, J. Power Sources, 2016, 302, 164173. 